\title{
Surgical management of hydrocephalus secondary to intraventricular hemorrhage in the preterm infant
}

\author{
Eisha A. Christian, MD, ${ }^{1}$ Edward F. Melamed, BA, ${ }^{2}$ Edwin Peck, MD, ${ }^{1}$ Mark D. Krieger, MD,,${ }^{1,2}$ and \\ J. Gordon McComb, MD ${ }^{1,2}$
}

\begin{abstract}
'Department of Neurosurgery, Keck School of Medicine, University of Southern California; and 'Division of Neurosurgery, Children's Hospital, Los Angeles, California
\end{abstract}

\begin{abstract}
OBJECTIVE Posthemorrhagic hydrocephalus $(\mathrm{PHH})$ in the preterm infant remains a major neurological complication of prematurity. The authors first described insertion of a specially designed low-profile subcutaneous ventricular catheter reservoir for temporary management of hydrocephalus in 1983. This report presents the follow-up experience with the surgical management of $\mathrm{PHH}$ in this population and describes outcomes both in infants who were stable for permanent shunt insertion and those initially temporized with a ventricular reservoir (VR) prior to permanent ventriculoperitoneal (VP)/ventriculoatrial (VA) shunt placement.
\end{abstract}

METHODS A retrospective review was undertaken of the medical records of all premature infants surgically treated for posthemorrhagic hydrocephalus (PHH) between 1997 and 2012 at Children's Hospital Los Angeles.

RESULTS Over 14 years, 91 preterm infants with PHH were identified. Fifty neonates received temporizing measures via a VR that was serially tapped for varying time periods. For the remaining 41 premature infants, VP/VA shunt placement was the first procedure. Patients with a temporizing measure as their initial procedure had undergone CSF diversion significantly earlier in life than those who had permanent shunting as the initial procedure ( 29 vs 56 days after birth, $p<0.01)$. Of the infants with a VR as their initial procedure, $5 / 50(10 \%)$ did not undergo subsequent VP/VA shunt placement. The number of shunt revisions and the rates of loculated hydrocephalus and shunt infection did not statistically differ between the 2 groups.

CONCLUSIONS Patients with initial VR insertion as a temporizing measure received a CSF diversion procedure significantly earlier than those who received a permanent shunt as their initial procedure. Otherwise, the outcomes with regard to shunt revisions, loculated hydrocephalus, and shunt infection were not different for the 2 groups.

http://thejns.org/doi/abs/10.3171/2015.6.PEDS15132

KEY WORDS intraventricular hemorrhage; posthemorrhagic hydrocephalus; preterm infant; ventricular reservoir; ventriculoperitoneal shunt

$\mathrm{I}$ NTRAVENTRICULAR hemorrhage (IVH) in the premature neonate remains a major complication of prematurity. Although its etiology is multifactorial, IVH is usually preceded by a hypoxic-ischemic insult followed by destruction of neuronal and glial precursors in the germinal matrix, with a varying degree of parenchymal destruction and the possible development of hydrocephalus. ${ }^{13}$ Initial management of IVH is aimed at preventing further damage to the neonatal brain and is primarily achieved by maintaining adequate cerebral perfusion. The reported in- cidence of IVH in preterm very-low-birth-weight infants $(<1500 \mathrm{~g})$ has decreased from $50 \%$ in the early 1980 s to around $20 \%$ in $2005 .{ }^{8}$ However, the incidence of posthemorrhagic hydrocephalus $(\mathrm{PHH})$ requiring treatment has remained stable across the country and is reported to be $25 \%-50 \%$ in patients with IVH. ${ }^{5}$

$\mathrm{PHH}$ is a complicated condition for which there is no consensus regarding optimal timing or type of surgical intervention, and the sequelae of chronic neurological deficits persist despite appropriate intervention. Often the initial

ABBREVIATIONS IVH = intraventricular hemorrhage; $\mathrm{LP}=$ lumbar puncture; $\mathrm{NEC}=$ necrotizing enterocolitis; $\mathrm{PHH}=$ posthemorrhagic hydrocephalus; $\mathrm{VA}=$ ventriculoatrial; VP = ventriculoperitoneal; VR = ventricular reservoir; VSG = ventriculosubgaleal.

SUBMITTED March 4, 2015. ACCEPTED June 18, 2015.

INCLUDE WHEN CITING Published online November 13, 2015; DOI: 10.3171/2015.6.PEDS15132. 
method of treating progressive $\mathrm{PHH}$ is with serial lumbar punctures (LPs). This method can be successful with Grades 1 and 2 bleeds but frequently fails in those neonates with Grades 3 and 4 hemorrhages, because the blood and debris obstruct CSF flow from the ventricles to the lumbar subarachnoid space. If this occurs, sometimes serial ventricular punctures are used; however, this can lead to additional parenchymal damage and possible porencephaly at the aspiration site. ${ }^{69}$ For this reason, it is believed better to insert a ventricular access device that only traverses the cortical mantle on a single occasion. A consideration in using a temporary means of CSF drainage is that a given number of these preterm infants develop necrotizing enterocolitis (NEC) that leads to bowel perforation. If a peritoneal catheter is present when this occurs, it can lead to gram-negative ventriculitis with devastating effects on the brain. For this reason, a ventriculoperitoneal (VP) shunt is not inserted until the infant is feeding well and is past the stage when NEC can develop. This usually occurs when the infant reaches a weight of $1500 \mathrm{~g}$, and as a result, we usually do not insert a VP shunt until this milestone is reached.

The insertion of a ventricular reservoir (VR) to intermittently remove CSF was described as a treatment for preterm infants with $\mathrm{PHH}$ at our institution in $1983^{6}$ and is often the temporizing measure of choice for treatment of PHH. ${ }^{8}$ More recently, the placement of a ventriculosubgaleal (VSG) shunt as another temporizing neurosurgical procedure to control progressive hydrocephalus after IVH has been developed as an alternate to a VR. A recent retrospective review showed no difference in complication rates or requirements for subsequent shunt placement in infants treated with VSG shunts compared with those receiving VRs. ${ }^{5}$

In 1983, we reported that early implementation of a VR reduced the rate of apnea and bradycardia in infants with progressive PHH. ${ }^{6}$ In a 1997 follow-up study at our institution, Levy et al. ${ }^{4}$ showed that despite treatment, grade of hemorrhage was the best predictor of long-term cognitive and motor outcome and did not appear to be noticeably improved with aggressive treatment of the resulting hydrocephalus.

It has also been speculated that removal of the resulting debris from the hemorrhage and necrotic brain via a VR may reduce the need for permanent CSF diversion, and if one is needed, it may diminish the need for subsequent shunt revisions or reduce the inflammatory response that can lead to loculated hydrocephalus. We report the experience of our institution and the outcomes of our patients with $\mathrm{PHH}$ over the course of 14 years with a focus on the impact of temporizing CSF drainage measures on shunt infection, revision, and loculation rates.

\section{Methods \\ Patient Population}

Approval by the Children's Hospital of Los Angeles Institutional Review Board was obtained prior to initiation of this study. A retrospective review of our records identified 91 preterm, low-birth-weight infants with $\mathrm{PHH}$ who received either temporary (VR) or permanent (VP/VA) CSF diversionary procedures between January 1997 and
December 2012. Cranial ultrasonography, CT, and MRI were used for grading infants' hemorrhages and to follow ventricular size.

All patients had been transferred from outside hospitals. Infants with progressive and marked ventriculomegaly and symptomatic hydrocephalus (clinically significant apneas and bradycardias) received a VR if they weighed less than $1500 \mathrm{~g}$; we have previously described placement and management of these catheter reservoirs. ${ }^{6}$ If these infants weighed more than $1500 \mathrm{~g}$, tolerated feedings, were past the point of possibly developing NEC, and were otherwise stable, a VP shunt was inserted. Vancomycin (15 $\mathrm{mg} / \mathrm{kg}$ every 12 hours for 24 hours) remained our perioperative antibiotic of choice. All attending surgeons at the Children's Hospital of Los Angeles followed the same protocol during this study interval.

\section{Outcome Measures and Data Analysis}

Primary outcome measures for this study included the development of shunt infection, malfunction, and loculated hydrocephalus. We focused on infections occurring within 6 months from insertion of a permanent shunt. Loculated hydrocephalus was defined by the presence of additional CSF compartments requiring either fenestration or shunt insertion. Patients with a minimum 1-month follow-up were included in the analysis of revisions and loculated hydrocephalus. The analysis of infections occurring within the first 6 months included all patients.

Additional parameters included gestational age, sex, birth weight, IVH grade, initial procedure, days to temporary and permanent CSF diversion, and months to revision. Statistical tools included the chi-square contingency table, Student t-test, univariate ANOVA, Mann-Whitney test, bivariate correlation, binomial regression, and Kaplan-Meier survival curve, with $\mathrm{p} \leq 0.05$ considered significant. SPSS (version 21, IBM) and SPSS SamplePower were used to conduct all statistical tests.

\section{Results}

\section{Patient Demographics}

Ninety-one preterm infants with $\mathrm{PHH}$ were identified from our records (Table 1). There were 58 males and 33 females. Birth weight ranged from $385 \mathrm{~g}$ to $3285 \mathrm{~g}$ (mean $1123 \pm 576 \mathrm{~g}$ ). Gestational age ranged from 22 weeks to 36 weeks (mean $27 \pm 4$ weeks). IVH was graded according to the Papile classification. ${ }^{7}$ The distribution was as follows: Grade 1 (1/91), Grade 2 (4/91), Grade 3 (36/91), and Grade 4 (48/91); 2/91 patients had no grade specified in their records.

Admissions per year were highest in 1997 with 17 patients and have since plateaued to 5-6 neonates per year from 2006 to 2012 (Fig. 1). The mean follow-up duration was 7 years (76 patients) with 9 deaths and 6 patients lost to follow-up. Seventy-five of 76 patients had a minimum follow-up of 6 months.

\section{Initial Procedure}

Seven patients $(8 \%)$ received serial LPs at outside hospitals prior to transfer to our institution. Three of these patients required VR insertion on admission to our facil- 
TABLE 1. Patient demographics*

\begin{tabular}{|c|c|c|}
\hline Initial Procedure & $\begin{array}{c}\text { Temporary } \\
\text { Drainage (\%) }\end{array}$ & $\begin{array}{c}\text { Permanent } \\
\text { Shunt (\%) }\end{array}$ \\
\hline Total & $50(100)$ & $41(100)$ \\
\hline \multicolumn{3}{|l|}{ Sex } \\
\hline Female & $19(38)$ & $14(34)$ \\
\hline Male & $31(62)$ & $27(66)$ \\
\hline \multicolumn{3}{|l|}{ Gestational age (wks) } \\
\hline Extremely preterm (<28) & $41(82)$ & $16(39)$ \\
\hline Very preterm (28-31) & $8(16)$ & $13(32)$ \\
\hline Moderately preterm (32-33) & 0 & $2(5)$ \\
\hline Late preterm (34-37) & $1(2)$ & $10(24)$ \\
\hline Mean birth weight \pm SD $(g)$ & $905 \pm 412$ & $1448 \pm 622$ \\
\hline \multicolumn{3}{|l|}{ Birth weight (g) } \\
\hline$<1000$ & $36(72)$ & $8(20)$ \\
\hline $1001-1250$ & $8(16)$ & $6(14)$ \\
\hline $1251-1500$ & $3(6)$ & $8(20)$ \\
\hline$>1500$ & $2(4)$ & $11(26)$ \\
\hline Missing & $1(2)$ & $8(20)$ \\
\hline \multicolumn{3}{|l|}{ IVH Grade } \\
\hline 1 & $1(2)$ & 0 \\
\hline 2 & 0 & $4(10)$ \\
\hline 3 & $23(46)$ & $13(32)$ \\
\hline 4 & $26(52)$ & $22(53)$ \\
\hline Missing & 0 & $2(5)$ \\
\hline $\begin{array}{l}\text { Mean time from birth to CSF diversion } \\
\pm S D \text { (days) }\end{array}$ & $29 \pm 9$ & $56 \pm 46$ \\
\hline
\end{tabular}

ity; 4 patients received VP shunts. Fifty patients received a temporary CSF drainage measure (VR) as their first CSF diversion procedure at our hospital between 10 days and 51 days of life (mean $29 \pm 9$ days). Forty-one patients weighed more than $1500 \mathrm{~g}$ on admission and received a VP or VA shunt at an average of 56 days after birth (range 8-211 days).

Patients with VR as their initial procedure received a CSF diversion procedure significantly earlier than patients with initial VPS/VAS insertion did (29 days vs 56 days, $p$ $<0.01$ ). Initial procedure (temporary vs permanent shunt) did not significantly impact the subsequent development of shunt malfunction $(\mathrm{p}=0.6)$, loculated hydrocephalus $(p=0.6)$, infections within 6 months $(p=0.2)$, revisions without infections $(\mathrm{p}=0.3)$, and number of revisions $(\mathrm{p}=$ $0.5)$ per patient.

\section{Shunt Independence}

Five patients $(10 \%)$ with temporary CSF diversion did not require the insertion of a VP/VA shunt at any time thereafter (Table 2). Of this group, 1 of the 5 patients had Grade 3 IVH and 4 of 5 had Grade 4 IVH.

\section{Mortality Rate}

Nine patients (10\%) died during their initial hospital-

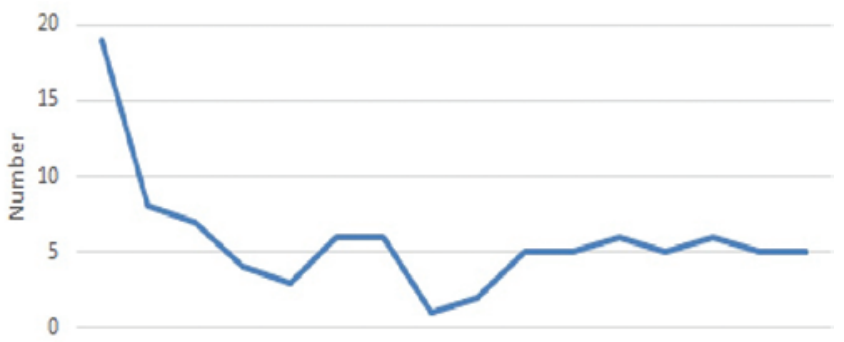

1997199819992000200120022003200420052006200720082009201020112012

Year

FIG. 1. Graph of annual admission of preterm infants with $\mathrm{PHH}$ requiring intervention. Figure is available in color online only.

ization (Table 3); no deaths were related to hydrocephalus or shunt insertion. Eight of these 9 patients (89\%) had a birth weight less than $1500 \mathrm{~g}$; the only patient with a higher birth weight died due to congenital cardiac defects. Two patients had small bowel perforations; neither patient had a VP shunt.

\section{Shunt Infection}

We reviewed shunt infection rates within 6 months of initial implantation. Ten patients, including both the VR group and VP/VA shunt group, presented with CSF infection (133 procedures). Three patients with a permanent shunt as the initial procedure (39 procedures, 8\%), and 7 patients with temporary CSF diversion (94 procedures, 7\%) developed infections within 6 months. Two patients with a VR developed infections during the period of serial taps: 1 patient had a gastric perforation with treated sepsis prior to VR insertion, and the second patient had NEC prior to VR insertion. Organisms included Staphylococcus aureus (1/10), Enterobacter (2/10), Escherichia coli $(2 / 10)$, and Group B Streptococcus $(1 / 10)$, and for 5 patients, this information was not documented. There was no statistically significant difference between rates of infection in patients who received a permanent shunt versus a temporizing measure $(\mathrm{p}=0.2)$. However, at $80 \%$ power, more than 10,000 patients would be required to power this analysis. Gestational age $(\mathrm{p}=0.4)$, sex $(\mathrm{p}=0.5)$, birth weight $(p=0.95)$, and IVH grade $(p=0.8)$ did not significantly impact infection rates (Table 4).

\section{Development of Loculated Hydrocephalus}

Eleven patients developed loculated hydrocephalus as

TABLE 2. Characteristics of patients who were able to absorb enough CSF and not require a permanent shunt

\begin{tabular}{ccccccc}
\hline Patient & Sex & BW (g) & $\begin{array}{c}\text { GA } \\
\text { (wks) }\end{array}$ & $\begin{array}{c}\text { Initial } \\
\text { Procedure }\end{array}$ & $\begin{array}{c}\text { IVH } \\
\text { Grade }\end{array}$ & $\begin{array}{c}\text { DOL at Reservoir } \\
\text { Insertion }\end{array}$ \\
\hline 1 & F & 987 & 27 & VR & 4 & 10 \\
\hline 2 & F & 642 & 24 & VR & 4 & 17 \\
\hline 3 & F & 902 & 27 & VR & 3 & 19 \\
\hline 4 & M & 1569 & 28 & LP, VR & 4 & 25 \\
\hline 5 & M & 1040 & 27 & VR & 4 & 26 \\
\hline
\end{tabular}

$\mathrm{BW}=$ birth weight; $\mathrm{DOL}=$ day of life; $\mathrm{GA}=$ gestational age . 
TABLE 3. Patients who died during their initial hospitalization

\begin{tabular}{ccccccll}
\hline Patient & Sex & BW (g) & GA (wks) & Apgar Score (1/5) & IVH Grade & Initial Procedure & Cause of Death \\
\hline 1 & F & 2500 & 34 & $8 / 8$ & 2 & VP shunt & Cardiac complications \\
\hline 2 & M & 1270 & 29 & $2 / 4$ & 4 & VP shunt & Hepatic failure, lung disease \\
\hline 3 & F & 680 & 23 & $2 / 7$ & 4 & VR & Pre-existing fungemia and withdrawal of care \\
\hline 4 & M & 582 & 24 & $1 / 5$ & 3 & VR, VA shunt & Pre-existing fungemia, gastrointestinal complications \\
\hline 5 & M & 860 & 24 & $4 / 5$ & 3 & VR, VP shunt & Interstitial pneumonia, cardiopulmonary arrest \\
\hline 6 & M & 591 & 26 & $5 / 5$ & 3 & VR, VA shunt & Necrotizing enterocolitis w/ bowel perforation and sepsis \\
\hline 7 & F & 750 & 25 & $2 / 3$ & 4 & VR & Unrelated complications \\
\hline 8 & M & 385 & 23 & $2 / 5$ & 4 & VR & Cardiac complications \\
\hline 9 & M & 680 & 22 & $4 / 6$ & 3 & VR & Bowel perforation/sepsis \\
\hline
\end{tabular}

defined by the need for an additional procedure, including fenestration or shunt to address the loculated compartment (Table 5); 5 patients had documented and treated ventriculitis prior to development of these loculations. Of the 6 remaining patients, 4 had VR as their initial procedure and 2 had VP shunt insertions. These 11 patients had an average of 2.5 procedures after diagnosis of compartmentalized hydrocephalus. The mean time to development of loculated hydrocephalus was 2.5 years. Gestational age ( $p$ $=0.3)$, sex $(\mathrm{p}=0.2)$, birth weight $(\mathrm{p}=0.7)$, IVH grade $(\mathrm{p}$ $=0.7)$, initial procedure $(\mathrm{p}=0.6)$, days to CSF diversion (both temporary and permanent, $\mathrm{p}=0.9$ ), and days to permanent shunt $(\mathrm{p}=0.4)$ after temporary CSF drainage did not significantly impact rates of loculated hydrocephalus (Table 5).

\section{VP Shunt Revision Rates}

Of our 76 patients with an average of 7 years of followup, 34 patients $(45 \%)$ required 1 or more revisions. Patients who died $(n=9)$ and patients lost to follow-up $(n=6)$ were excluded. There was no difference in revisions between patients with temporary CSF drainage prior to shunt insertion and those with initial permanent VP/VA shunt insertion $(44 \%$ vs $39 \%, p=0.6)$. However, at $80 \%$ power, 1500 patients are required to power this analysis. Revisions per month were also analyzed: patients with initial VP shunt insertion had a rate of 0.02 revisions per month versus 0.03 revisions per month in the VR subgroup ( $p$ $=0.26)$. Gestational age $(\mathrm{p}=0.06)$, sex $(\mathrm{p}=0.10)$, birth weight $(\mathrm{p}=0.08)$, IVH grade $(\mathrm{p}=0.1)$, days to CSF diver- sion $(\mathrm{p}=0.3)$, and permanent shunt insertion $(\mathrm{p}=0.6)$ did not impact the overall revision rate. A subgroup analysis of the 28 patients who had shunt malfunction without a preceding infection also showed no significant impact of these factors except for IVH grade $(p=0.04)$. Additional subgroup analysis using dichotomized birth weight categories of less than or greater than $1500 \mathrm{~g}$ showed that only 1 infant weighing more than $1500 \mathrm{~g}$ had a revision without a preceding infection.

We also looked at VA shunt revision rates (Table 6): 5 patients received VA shunts due to gastrointestinal complications (NEC/perforated bowel). Two patients died during the same admission from sepsis. The 3 surviving patients required revision to a VP shunt within 1 year.

\section{Discussion}

We described the management of PHH in the preterm infant with a subcutaneous ventricular catheter reservoir in $1983 .{ }^{6}$ The reservoir was serially accessed for as long as 7 weeks, and our first series of 20 patients admitted between 1977 and 1979 had no VR- or VP shunt-related infections or skin breakdowns. Of note, we had a $65 \%$ mortality rate (unrelated to hydrocephalus) in this series. A follow-up study published in 1997 documented a $7 \%$ infection rate per patient of either the reservoir or VP shunt and a mortality rate of $41 \% .{ }^{4}$ In this series, 2 reservoirs became infected, 1 neonate who had septicemia with the same organism and the second after adjacent scalp necrosis following infiltration of a calciumcontaining solution that led to exposure of the reservoir.

TABLE 4. Revision, infection, and loculation risk analysis

\begin{tabular}{lcccc}
\hline \multicolumn{1}{c}{ Variable } & $\begin{array}{c}\text { Overall Revision } \\
\text { Rate }\end{array}$ & $\begin{array}{c}\text { Revision w/o } \\
\text { Preceding Infection }\end{array}$ & $\begin{array}{c}\text { Loculated } \\
\text { Infection Rate }\end{array}$ & \begin{tabular}{c} 
Hydrocephalus \\
\hline Gestational age
\end{tabular} \\
\hline Sex & NS & NS & NS & NS \\
\hline Birth weight & NS & NS & NS & NS \\
\hline IVH grade & NS & p $=0.04$ & NS & NS \\
\hline Days to CSF diversion & NS & NS & NS & NS \\
\hline Initial procedure: temporary vs permanent & NS & NS & NS & NS \\
\hline
\end{tabular}

NS = not significant. 
TABLE 5. Characteristics of patients with loculated hydrocephalus

\begin{tabular}{|c|c|c|c|c|c|c|c|c|}
\hline Patient & Sex & BW (g) & $\mathrm{GA}$ (wks) & Prior Infection & IVH Grade & Procedure & Days to CSF Diversion & Days to Shunt \\
\hline 1 & M & NR & 26 & Yes & 4 & VP shunt & 33 & \\
\hline 2 & $\mathrm{~F}$ & 655 & 25 & Yes & 1 & VR, VP shunt & 18 & 54 \\
\hline 3 & $\mathrm{~F}$ & 645 & 26 & No & 4 & VR, VP shunt & 33 & 31 \\
\hline 4 & $\mathrm{~F}$ & 1184 & 27 & No & 3 & VR, VP shunt & 15 & 47 \\
\hline 5 & M & 794 & 26 & No & 4 & VP shunt & 67 & \\
\hline 6 & M & 1170 & 28 & Yes & 3 & VP shunt & 34 & \\
\hline 7 & $\mathrm{~F}$ & NR & 23 & Yes & 4 & VP shunt & 146 & \\
\hline 8 & $\mathrm{~F}$ & NR & 25 & No & 4 & VR, VP shunt & 18 & 72 \\
\hline 9 & M & 2500 & 33 & No & 3 & VP shunt & 8 & \\
\hline 10 & $\mathrm{~F}$ & 1020 & 27 & Yes & 4 & VP shunt & 48 & \\
\hline 11 & $M$ & 648 & 25 & No & 3 & VR, VP shunt & 28 & 67 \\
\hline
\end{tabular}

$\mathrm{NR}=$ not recorded

No reservoir infection appeared to be related to the serial tapping procedure.

Our current study reviews preterm infants with $\mathrm{PHH}$ from 1997 to 2012 who received either temporary (VR) or permanent (VP/VA shunt) CSF diversionary procedures. Unlike our previous work, this study included patients who were stable and weighed enough for permanent shunt insertion; our overall mortality rate was $10 \%$ (the VR subgroup had a mortality rate of $14 \%$ ). In addition to a declining mortality rate, the rate of admission for $\mathrm{PHH}$ at our institution has decreased from 17 patients in 1997 to 5-6 admissions per year since 2006. National admissions appear to vary by region and hospital: St. Louis Children's Hospital reported increasing numbers, ${ }^{5}$ while Rainbow Babies and Children's Hospital in Cleveland reported a 3 -fold drop over the last decade. ${ }^{8}$

\section{CSF Absorption}

Five patients $(10 \%)$ with temporary CSF drainage did not require permanent shunt insertion. There have been multiple studies assessing the need for a permanent shunt in patients with a VR, and the rates of shunt dependence range from $69 \%$ to $93 \% .^{3-5,14,15}$ Given that 1 of 10 patients in our series did not require a shunt after temporary drainage, a trial of CSF drainage in selective cases may be warranted before the insertion of a permanent VP/VA shunt. In our cohort, 1 asymptomatic 4-year-old patient with stable ventricular size who received a shunt was incidentally discovered on routine follow-up to have peritoneal tubing broken just distal to the valve, with migration of the re- mainder of the catheter to the abdominal cavity, rendering the shunt nonfunctional. It is suspected that a given percentage of these patients slowly obstruct their shunt and thus become independent of its presence. As the ability to reliably assess this in the VP/VA shunt population is difficult and invasive, we have not tried to do so.

\section{Shunt Infections}

There has been a concern that tapping the reservoir may lead to infection. Within our cohort, we found no statistically significant difference in the rate of infection between a VR and a VP/VA shunt as the initial procedure. However, more than 10,000 patients would be required to conclusively determine if there was a difference between the 2 groups. Additional analysis did not find an association between duration of the tapping period and infection rate. Kormanik et al. ${ }^{2}$ previously demonstrated no association between frequent tapping of a VR and CSF infection. However, Spader et al. ${ }^{11}$ recently reported on their series of 105 patients with VRs: they reported an overall infection rate of $10.5 \%$, with gestational age at procedure and preexisting meningitis being significant risk factors for VR infections. VRs and VSG shunts also demonstrated no difference in device infection between the 2 groups ${ }^{1,3,14}$ even though VSG shunts are accessed much less frequently than VRs. A recent review of infections following tapping of the reservoir found the incidence to be either very low or negligible. ${ }^{12}$ We are therefore not concerned about causing an infection when the reservoir tapping is properly performed.

TABLE 6. Characteristics of patients with VA shunts

\begin{tabular}{cccccll}
\hline Patient & Sex & BW (g) & GA (wks) & IVH Grade & Initial Procedure & Outcome \\
\hline 1 & M & 582 & 24 & 3 & VR, VA shunt & Deceased, pre-existing fungemia, gastrointestinal complications \\
\hline 2 & M & 591 & 26 & 3 & VR, VA shunt & Deceased, necrotizing enterocolitis w/ bowel perforation and sepsis \\
\hline 3 & M & 660 & 23 & 3 & VR, VA shunt & VA shunt, VP shunt, ventriculocholecystic shunt in 1 yr \\
\hline 4 & M & 902 & 25 & 4 & VR, VA shunt & VA shunt, VP shunt in 1 yr \\
\hline 5 & F & 820 & 26 & 3 & VR, VA shunt & VA shunt, VP shunt in 1 yr \\
\hline
\end{tabular}




\section{Loculated Hydrocephalus}

Multiloculated hydrocephalus has most commonly been associated with CNS infection and IVH..$^{10}$ Eleven of 76 of our patients with long-term follow-up developed loculated hydrocephalus and $5(45 \%)$ of these patients had a CNS infection prior to development of their loculations. Of the remaining 6 patients, 4 had a VR as their initial procedure and 2 had a VP shunt; this finding implies that VRs do not necessarily decrease risk of loculated compartments. However, our small subset of 6 patients in this sample precludes a definitive conclusion. This patient population, however, deserves closer attention given that they are at higher risk for multiple subsequent procedures.

\section{Revision Rates}

Willis et al. ${ }^{16}$ report a lower shunt revision rate for the VR group than the VP shunt group in their series of 32 patients. In contrast, we found no statistically significant difference between these groups in our series of 91 patients (Table 4). Again, more than 1500 neonates with PHH are needed to adequately power this analysis. Furthermore, the duration of temporary CSF diversion (i.e., the number of days prior to shunt insertion) was not different between patients with and without revisions. We also performed a subgroup analysis on patients who underwent a revision procedure without a preceding infection to focus on revisions related to the primary procedure and not to those potentially related to infection; IVH grade was the only factor that had a significant impact on this outcome even though the results showed that patients with Grade 3 IVH had a higher rate of revisions $(50 \%)$ versus those with Grade 4 IVH (23\%; Table 4).

An additional subgroup analysis was conducted on patients who, due to preexisting gastrointestinal complications such as NEC with perforated bowel, received a VA shunt. Of note, 2 of 5 patients died during the same admission for sepsis related to their bowel perforation. The remaining 3 patients required revision to a VP shunt within 1 year of insertion of their VA shunt.

\section{Limitations of the Study}

This study has limitations that are inherent to any single-center retrospective study and is not powered to make a conclusive statement on the difference between neonates who receive permanent shunting versus those who receive a temporizing measure prior to the insertion of a permanent shunt. This study reviews the outcomes of a large single-center institution with a standardized protocol, thereby reducing clinical variability. However, to show a statistically significant difference $(\mathrm{p}<0.05$, power $=80 \%)$ between revision rate and infections, 1500 and 10,000 patients, respectively, would be required and emphasizes the importance of multicenter collaborative studies.

\section{Conclusions}

Treatment of preterm infants with IVH and hydrocephalus continues to be complicated with no consensus on optimal surgical management. We have shown that the VR continues to be a safe method of temporary drainage with $10 \%$ of our patient population remaining shunt in- dependent. Patients with a temporizing measure of CSF drainage received a CSF diversion procedure significantly earlier in life than those who received a permanent shunt as their initial procedure. We found no difference in outcomes of infection, revisions, and loculated hydrocephalus between patients who received temporary CSF drainage versus patients who received a permanent shunt as their initial procedure, but large multicenter studies are needed to further validate these results.

\section{References}

1. Brouwer AJ, Groenendaal F, van den Hoogen A, VerboonMaciolek M, Hanlo P, Rademaker KJ, et al: Incidence of infections of ventricular reservoirs in the treatment of posthaemorrhagic ventricular dilatation: a retrospective study (1992-2003). Arch Dis Child Fetal Neonatal Ed 92:F41F43, 2007

2. Kormanik K, Praca J, Garton HJ, Sarkar S: Repeated tapping of ventricular reservoir in preterm infants with post-hemorrhagic ventricular dilatation does not increase the risk of reservoir infection. J Perinatol 30:218-221, 2010

3. Lam HP, Heilman CB: Ventricular access device versus ventriculosubgaleal shunt in post hemorrhagic hydrocephalus associated with prematurity. J Matern Fetal Neonatal Med 22:1097-1101, 2009

4. Levy ML, Masri LS, McComb JG: Outcome for preterm infants with germinal matrix hemorrhage and progressive hydrocephalus. Neurosurgery 41:1111-1118, 1997

5. Limbrick DD Jr, Mathur A, Johnston JM, Munro R, Sagar J, Inder T, et al: Neurosurgical treatment of progressive posthemorrhagic ventricular dilation in preterm infants: a 10-year single-institution study. J Neurosurg Pediatr 6:224-230, 2010

6. McComb JG, Ramos AD, Platzker AC, Henderson DJ, Segall HD: Management of hydrocephalus secondary to intraventricular hemorrhage in the preterm infant with a subcutaneous ventricular catheter reservoir. Neurosurgery 13:295300, 1983

7. Papile LA, Burstein J, Burstein R, Koffler H: Incidence and evolution of subependymal and intraventricular hemorrhage: a study of infants with birth weights less than 1,500 gm. J Pediatr 92:529-534, 1978

8. Robinson S: Neonatal posthemorrhagic hydrocephalus from prematurity: pathophysiology and current treatment concepts. J Neurosurg Pediatr 9:242-258, 2012

9. Salmon JH: Puncture porencephaly. Pathogenesis and prevention. Am J Dis Child 114:72-79, 1967

10. Sandberg DI, McComb JG, Krieger MD: Craniotomy for fenestration of multiloculated hydrocephalus in pediatric patients. Neurosurgery 57 (1 Suppl):100-106, 2005

11. Spader HS, Hertzler DA, Kestle JR, Riva-Cambrin J: Risk factors for infection and the effect of an institutional shunt protocol on the incidence of ventricular access device infections in preterm infants. J Neurosurg Pediatr 15:156-160, 2015

12. Spiegelman L, Asija R, Da Silva SL, Krieger MD, McComb JG: What is the risk of infecting a cerebrospinal fluid-diverting shunt with percutaneous tapping? J Neurosurg Pediatr 14:336-339, 2014

13. Strahle J, Garton HJ, Maher CO, Muraszko KM, Keep RF, Xi G: Mechanisms of hydrocephalus after neonatal and adult intraventricular hemorrhage. Transl Stroke Res 3 (Suppl 1):25-38, 2012

14. Wang JY, Amin AG, Jallo GI, Ahn ES: Ventricular reservoir versus ventriculosubgaleal shunt for posthemorrhagic hydrocephalus in preterm infants: infection risks and 
ventriculoperitoneal shunt rate. J Neurosurg Pediatr 14:447454, 2014

15. Wellons JC, Shannon CN, Kulkarni AV, Simon TD, RivaCambrin J, Whitehead WE, et al: A multicenter retrospective comparison of conversion from temporary to permanent cerebrospinal fluid diversion in very low birth weight infants with posthemorrhagic hydrocephalus. J Neurosurg Pediatr 4:50-55, 2009

16. Willis B, Javalkar V, Vannemreddy P, Caldito G, Matsuyama J, Guthikonda B, et al: Ventricular reservoirs and ventriculoperitoneal shunts for premature infants with posthemorrhagic hydrocephalus: an institutional experience. J Neurosurg Pediatr 3:94-100, 2009

\section{Disclosures}

The authors report no conflict of interest concerning the materi- als or methods used in this study or the findings specified in this paper.

\section{Author Contributions}

Conception and design: Christian, McComb. Acquisition of data: Christian. Analysis and interpretation of data: Christian, Melamed. Drafting the article: Christian, Melamed, Peck. Critically revising the article: Christian, Melamed, McComb. Reviewed submitted version of manuscript: Christian, Krieger, McComb. Approved the final version of the manuscript on behalf of all authors: Christian. Statistical analysis: Christian, Melamed. Administrative/technical/material support: Melamed. Study supervision: Christian, Krieger, McComb.

\section{Correspondence}

Eisha A. Christian, 1200 N. State St., Ste. 3300, Los Angeles, CA 90033.email: echristi@usc.edu. 